\title{
WaVE HeIGHT Measurements FROM HF RADAR
}

\section{Remote sensing of-}

fers the only opportu-

nity to obtain high-

resolution spatial in-

formation about the

shoaling wave field.

\author{
By Hans C. Graber and Malcolm L. Heron
}

$\mathrm{N}$ EARSHORE AND INNER SHELF dynamics are forced principally by radiation stress gradients induced by shoaling and breaking waves. Waves in shallow water refract due varying bottom topography. Thus the wave climate can vary significantly alongshore. Remote sensing offers the only opportunity to obtain high-resolution spatial information about the shoaling wave field.

The concept of using high-frequency (HF) radio pulses to probe the ocean surface to deduce nearsurface currents has received considerable attention in coastal oceanographic experiments. HF radar systems have been extensively used to measure or predict a range of oceanic processes from tidal currents (e.g., Prandle, 1991; Shay et al., 1995) to wind-induced surface flows $(\mathrm{Ng}, 1993)$. More recently, several studies (e.g., Heron et al., 1985; Wyatt, 1988) have focused on extracting additional information about the ocean surface from the Doppler spectrum measured by HF radar. Of particular interest is the height of ocean waves that plays a crucial role in engineering projects, ship navigation and design, and vessel traffic control in harbors as well as shoreline protection, beach erosion, and mitigation of oil spills and ocean pollution.

\section{Sea Echo Spectrum}

The sea echo spectrum measured by HF radars includes the effects of the full ocean wave spectrum. Barrick (1977a,b) has shown that the radar backscatter spectrum is nonlinearly related to the ocean wave spectrum. Extraction of the directional wave spectrum is possible with inverse techniques (e.g., see Wyatt, 1997, this issue). However, these methods are often computationally intensive. An alternative approach is to estimate the wave height from the first-order and second-order radar echoes by using characteristic properties of the spectrum. The square-root of the integral over the directional wave spectrum is di-

Hans C. Graber, Rosenstiel School of Marine and Atmospheric Science, University of Miami, Miami. FL 33149. USA. Malcolm L. Heron, School of Computer Science, Mathematics and Physics, James Cook University, Townsville, Queensland, 4811, Australia. rectly related to the rms wave height and is an important parameter used in many studies involving wave dynamics. Barrick (1977b) suggested a simple, yet accurate, method to obtain the rms wave height, $\mathrm{H}_{\text {rns }}$, from the total power in the first-order peak, $\mathrm{P}_{1}$ and the total power in the second-order weighted spectrum, $\mathrm{P}_{2}$. Specifically, this relationship can be expressed,

$$
H_{r m s}=\left[\frac{\lambda}{\sqrt{2} \pi} \frac{\int_{-x}^{\infty} \sigma_{2}(f) W^{-1}\left(f / f_{b}\right) d f}{\int_{-x}^{\infty} \sigma_{1}(f) d f}\right]^{1 / 2}
$$

where $f_{b}$ is the Bragg frequency, $\lambda$ is the radar wavelength, $W\left(f / f_{b}\right)$ is a weighting function, and $\sigma_{1}, \sigma_{2}$ are the first-order and second-order radar cross-sections.

Figure 1 shows a typical Doppler spectrum from ocean surface current radar (OSCR) obtained in DUCK94. On the plot are also indicated the limits of the first-order and inner and outer second-order Doppler regions.

S.F. Heron and M.L. Heron (unpublished data) evaluated several algorithms (e.g., Barrick, 1977: Maresca and Georges, 1980; Heron et al., 1985 ) based on this simple power law relationship with OSCR data obtained from the DUCK94 experiment. They found that the halfpower law, $\mathrm{H}_{\mathrm{rms}}=\alpha \lambda \mathrm{R}^{1 / 2}$, derived from Equation (1) is robust for rms wave heights as low as $20 \mathrm{~cm}$. Here $\alpha=\frac{1}{3}$ is an empirical constant, and R is a weighted ratio of the integrals in Equation (1).

\section{DUCK94 Data}

Heron (1996) has examined in detail the application of these three different power law relations for estimating wave heights with $\mathrm{HF}$ radar backscatter data acquired during DUCK94. He found that a modified version of Barrick's (1977b) algorithm (Eq. 1) provided the most accurate wave height estimates with a rms error of only $14 \mathrm{~cm}$ for wave heights ranging from $50 \mathrm{~cm}$ to $4 \mathrm{~m}$. The modified Barrick algorithm was applied to the entire DUCK94 data set that included significant wave 
heights, $\mathrm{H}_{1 / 3}=4 \mathrm{H}_{\mathrm{rms}}$, in excess of $6 \mathrm{~m}$ during a Nor'easter. Figure 2 shows a comparison of the significant wave height observed by a 3-m National Data Buoy Center (NDBC) discus buoy with those estimated from HF radar. The wave buoy was located $\sim 25 \mathrm{~km}$ offshore from the U.S. Army Corps of Engineers Field Research Facility at Duck, North Carolina in 30-m water depth. The agreement is remarkable especially during the growth and decay stages of several frontal passages and the midmonth extra-tropical storm system.

There are several times when the radar overshoots the buoy observations, especially during the storm peak. Some of this discrepancy is caused by broader signal return because of enhanced wave breaking. Interference and poor signal-to-noise ratio are also possible causes for the overestimation. Nevertheless, a statistical analysis with two other wave-measuring systems in the nearshore regime off Duck, North Carolina revealed a small overall positive bias of only $7 \mathrm{~cm}$ (i.e., radar wave heights are greater than the buoy measurements) and a rms error not exceeding $38 \mathrm{~cm}$ for a range of significant wave heights from 0.5 to $6 \mathrm{~m}$.

Figure 3 shows a sequence of four hourly averaged wave height maps derived from three 20-min OSCR Doppler spectra centered at 12:00, 15:00, 18:00, and 21:00 UT on 15 October 1994 during the peak of the Nor'easter. The maps delineate the spatial evolution of the storm-generated waves as they approach the shore. As the storm strengthened (12:00 and 15:00 UT) the wave heights appear to be uniform in the alongshore direction. Whereas, at the peak of the storm (18:00 and 21:00 UT), the influence of the bottom through shoaling and depth refraction is quite apparent displaying spatially variable wave heights over the inner shelf (water depth $\leq 25 \mathrm{~m}$ ).

\section{Conclusions}

Many advantages of HF radar wave observations exist over standard methods. In particular, the ability to sample a wide region in near real time substantially enhances many marine-related operations including search and rescue mission, oil spill clean up, and dredging operations. While inverse techniques (see Wyatt, 1997, this issue) provide more detail information about the directional distribution of ocean waves, the technique described here emphasizes efficiency and robustness. The need for sea state information around harbors and offshore facilities is crucial for safe and economical operations. In particular, harbor entrances and river mouths can pose treacherous conditions for small craft and medium size vessels when opposing currents (e.g., tides and river flow) interact with ocean waves (wave-current interaction). Furthermore, radar observations can also be made in adverse weather conditions, and the calculation of wave heights is independent of materials in the water. Consequently, such a technique could be used in re-

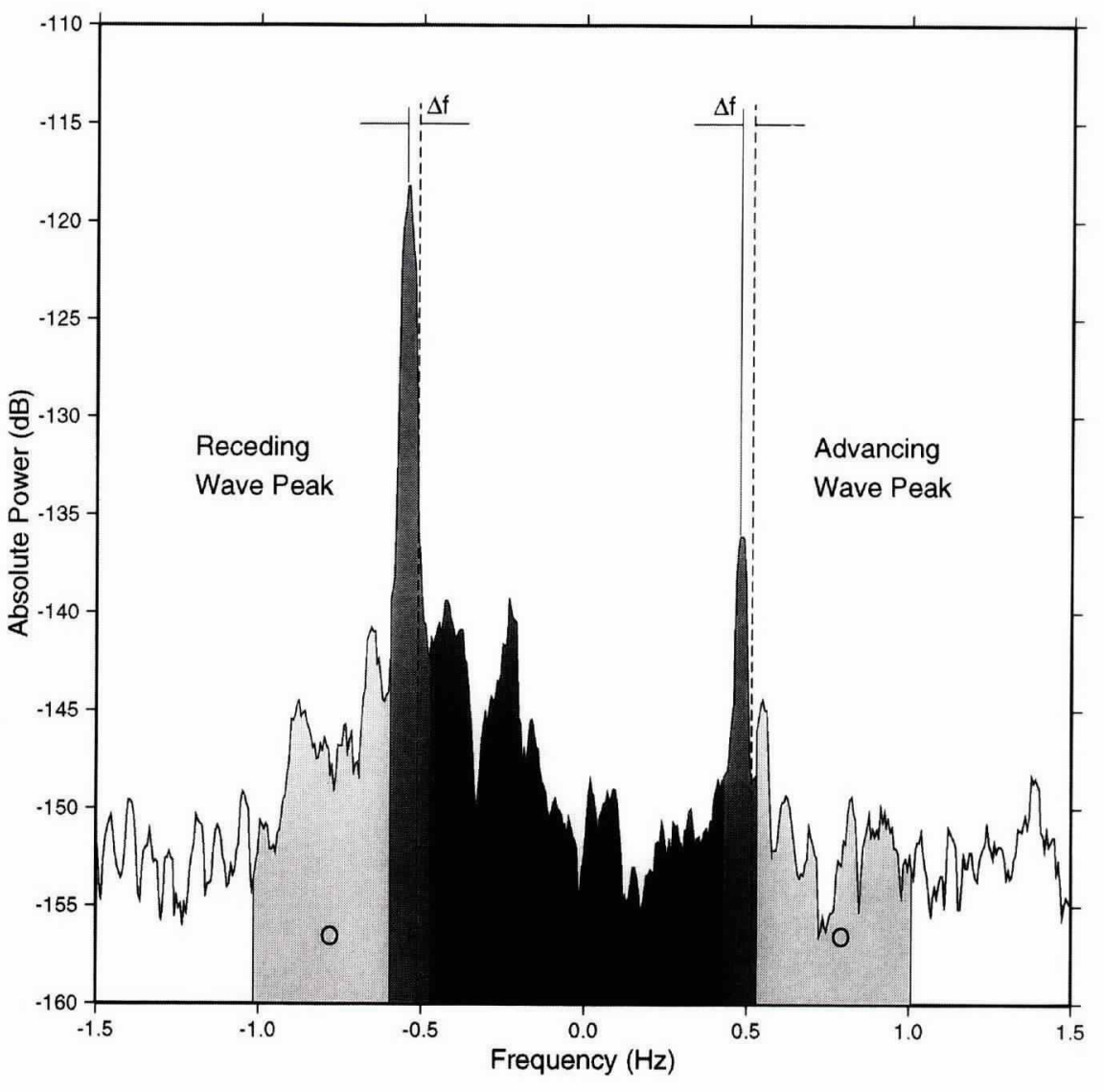

Fig. 1: A typical sea echo spectrum for $25.4 \mathrm{MHz}$ obtained by OSCR during the DUCK 94 experiment off the North Carolina coast in October 1994. The shaded regions indicate the first-order $(F)$, inner $(I)$, and outer $(O)$ second-order spectral bands.

IS buoy

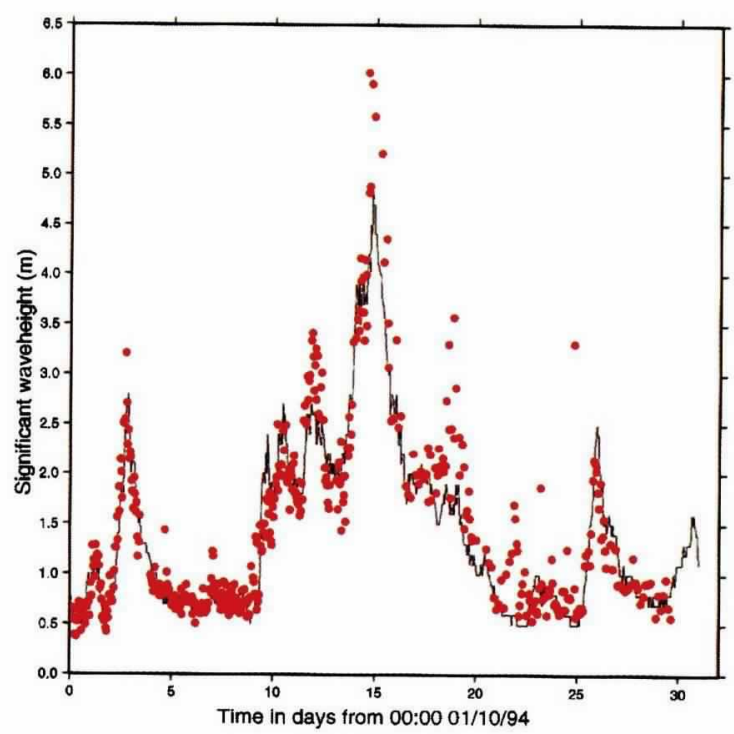

. . radar observa-

tions can also be

made in adverse

weather conditions,

and the calculation of

wave heights is inde-

pendent of materials

in the water. 

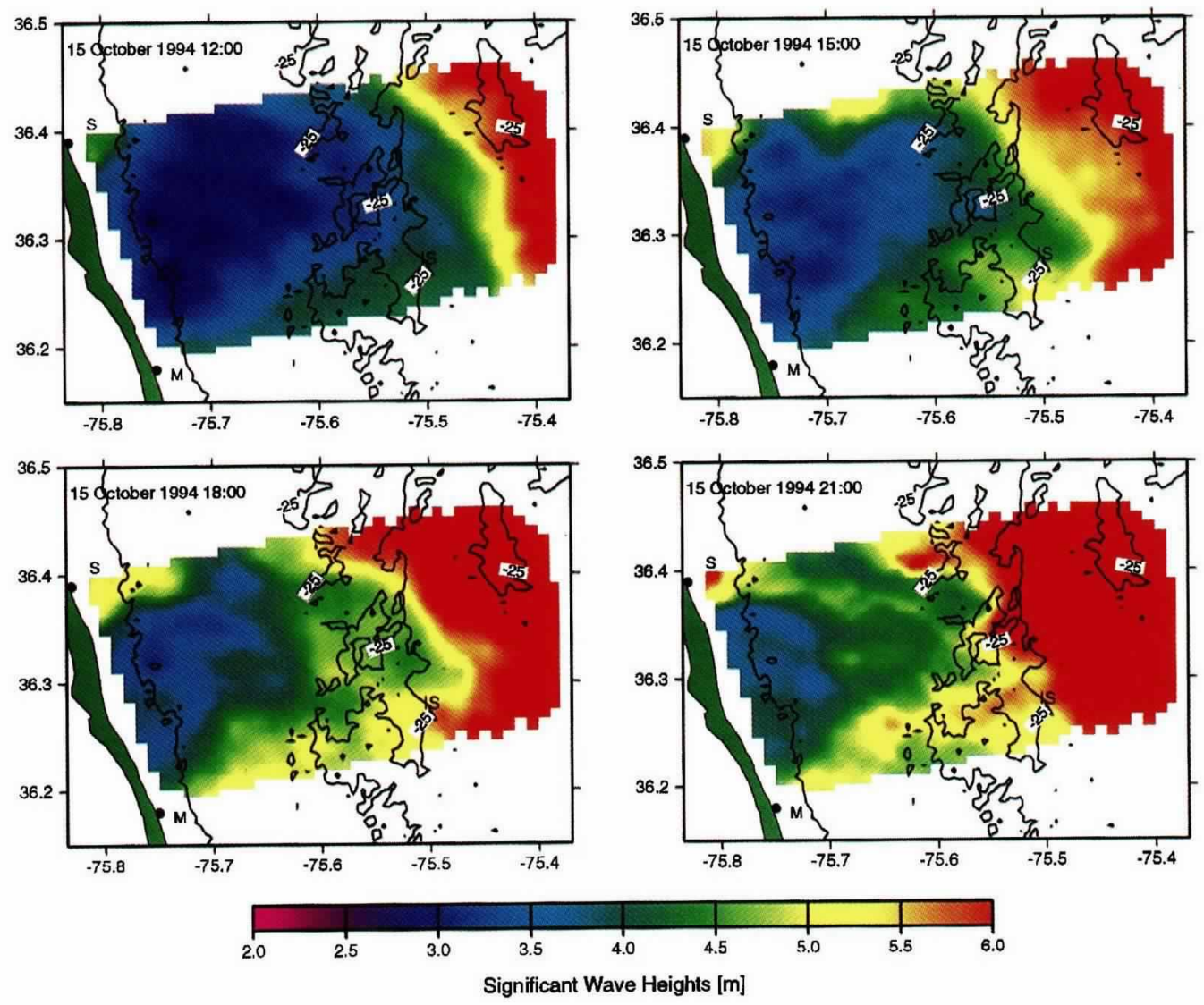

Fig. 3: The figure reveals the evolution and spatial variability of the wave field over the inner shelf with 6.0-m significant wave heights in the outer ranges and 2.5-m significant wave heights close to shore. The four snapshots are hourly-averaged wave height map from three 20-min OSCR observations during a Nor'easter off Duck, NC on 15 October 1994.

gions (e.g., river mouths, estuaries, nearshore, and inner shelf) where the presence of sediment or biological material in the water column could affect other sensors. During and after the passage of storms when biological activity and sediment resuspension is high, observations of the surface wave patterns are important to assess the impact on sediment transport and shoreline erosion.

\section{Acknowledgment}

The results discussed here were funded in part by the Office of Naval Research through grant N00014-94-1-1016 (DUCK94). The authors thank Brian Haus, Nick Shay, Jorge Martinez, and Nick Peters for the dedicated field work with OSCR. Scott Heron analyzed the extensive set of radar spectra, and Slavica Nikolic generated the graphics.

\section{References}

Barrick, D.E., 1977a: The ocean wave height non-directional spectrum from inversion of the HF sea-echo Doppler spectrum. Rem. Sens. Environ., 6, 201-227.

1977b: Extraction of wave parameters from measured HF sea echo Doppler spectra. Radio Sci., 12, 415-424.
Haus, B.K., H.C. Graber, L.K. Shay and J. Martinez, 1995: Ocean Surface Current Observations with HF Doppler Radar during the DUCK94 Experiment. Technical Report RSMAS 95-010, University of Miami, Miami, FL. 104 pp.

Heron, M.L., P.E. Dexter and B.T. McGann, 1985: Parameters of the air-sea interface by high-frequency ground-wave Doppler radar. Aust. J. Mar. Freshw. Res., 36, 655-670.

Heron, S.F., 1996: Waveheight analysis using HF radar. Honors Thesis, Department of Physics, James Cook University of North Queensland, $91 \mathrm{pp}$.

Maresca, J.W., Jr. and T.M. Georges, 1980: Measuring rms wave height and the scalar ocean wave spectrum with HF skywave radar. J. Geophys. Res., 85, 2759-2771.

$\mathrm{Ng}, \mathrm{B} ., 1993$ : The prediction of nearshore wind-induced surface currents from wind velocities measured at nearby land stations. J. Phys. Oceanogr., 23, 1609-1617.

Prandle, D. 1991. A new view of near-shore dynamics based on observations from HF radar. Prog. Oceanogr., 27, 403-438.

Shay, L.K., H.C. Graber, D.B. Ross and R.D. Chapman, 1995: Mesoscale ocean surface current structure detected by HF radar. J. Atmos. Ocean. Tech., 12, 881-900.

Wyatt, L.R., 1988: Significant waveheight measurement with h.f. radar. Int. J. Rem. Sens., 9, 1087-1095.

Wyatt, L.R., 1997: The ocean wave directional spectrum. Oceanography, 10, 85-89. 